\title{
22 About the National Institute of Child Health and Human Development in Israel
}

The National Institute of Child Health and Human Development (NICHD) in Israel was established in 1998 as a virtual institute under the auspicies of the Medical Director, Ministry of Social Affairs and Social Services in order to function as the research arm for the Office of the Medical Director. In 1998 the National Council for Child Health and Pediatrics, Ministry of Health and in 1999 the Director General and Deputy Director General of the Ministry of Health endorsed the establishment of the NICHD.

\subsection{Mission}

The mission of a National Institute for Child Health and Human Development in Israel is to provide an academic focal point for the scholarly interdisciplinary study of child life, health, public health, welfare, disability, rehabilitation, intellectual disability and related aspects of human development. This mission includes research, teaching, clinical work, information and public service activities in the field of child health and human development.

\subsection{Service and academic activities}

Over the years many activities became focused in the South of Israel due to collaboration with various professionals at the Faculty of Health Sciences (FOHS) at the Ben Gurion University of the Negev (BGU). Since 2000, an affiliation with the Zusman Child Development Center at the Pediatric Division of Soroka University Medical Center has resulted in collaboration around the establishment of the Down Syndrome Clinic at that center. In 2002, a full course on "Disability" was established at the Recanati School for Allied Professions in the Community, FOHS, BGU and in 2005 collaboration was started with the Primary Care Unit of the faculty and disability became part of the master of public health course on "Children and society." In the academic year 2005-2006, a one semester course on "Aging with disability" was started as part of the master of science program in gerontology in our collaboration with the Center for Multidisciplinary Research in Aging. In 2010 collaborations with the Division of Pediatrics, Hadassah Medical Center, Hebrew University, Jerusalem, Israel.

\subsection{Research activities}

The affiliated staff have over the years published work from projects and research activities in this national and international collaboration. In the year 2000, the 
International Journal of Adolescent Medicine and Health and in 2005 the International Journal on Disability and Human Development of De Gruyter Publishing House (Berlin and New York), in the year 2003 the TSW-Child Health and Human Development and in 2006 the TSW-Holistic Health and Medicine of the Scientific World Journal (New York and Kirkkonummi, Finland), all peer-reviewed international journals were affiliated with the National Institute of Child Health and Human Development. From 2008 also the International Journal of Child Health and Human Development (Nova Science, New York), the International Journal of Child and Adolescent Health (Nova Science) and the Journal of Pain Management (Nova Science) affiliated and from 2009 the International Public Health Journal (Nova Science) and Journal of Alternative Medicine Research (Nova Science).

\subsection{National collaborations}

Nationally the NICHD works in collaboration with the Faculty of Health Sciences, Ben Gurion University of the Negev; Department of Physical Therapy, Sackler School of Medicine, Tel Aviv University; Autism Center, Assaf HaRofeh Medical Center; National Rett and PKU Centers at Chaim Sheba Medical Center, Tel HaShomer; Department of Physiotherapy, Haifa University; Department of Education, Bar Ilan University, Ramat Gan, Faculty of Social Sciences and Health Sciences; College of Judea and Samaria in Ariel and in 2011 affiliation with Center for Pediatric Chronic Diseases and Center for Down Syndrome, Department of Pediatrics, Hadassah-Hebrew University Medical Center, Mount Scopus Campus, Jerusalem.

\subsection{International collaborations}

Internationally with the Department of Disability and Human Development, College of Applied Health Sciences, University of Illinois at Chicago; Strong Center for Developmental Disabilities, Golisano Children's Hospital at Strong, University of Rochester School of Medicine and Dentistry, New York; Centre on Intellectual Disabilities, University of Albany, New York; Centre for Chronic Disease Prevention and Control, Health Canada, Ottawa; Chandler Medical Center and Children's Hospital, Kentucky Children's Hospital, Section of Adolescent Medicine, University of Kentucky, Lexington; Chronic Disease Prevention and Control Research Center, Baylor College of Medicine, Houston; Division of Neuroscience, Department of Psychiatry, Columbia University, New York; Institute for the Study of Disadvantage and Disability, Atlanta; Center for Autism and Related Disorders, Department Psychiatry, Children's Hospital Boston, Boston; Department of Paediatrics, Child Health and Adolescent Medicine, Children's Hospital at Westmead, Westmead, Australia; International Centre for the Study of Occupational and Mental Health, Düsseldorf, Germany; Centre for Advanced 
Studies in Nursing, Department of General Practice and Primary Care, University of Aberdeen, Aberdeen, UK; Quality of Life Research Center, Copenhagen, Denmark; Nordic School of Public Health, Gottenburg, Sweden, Scandinavian Institute of Quality of Working Life, Oslo, Norway; Centre for Quality of Life of the Hong Kong Institute of Asia-Pacific Studies and School of Social Work, Chinese University, Hong Kong.

\subsection{Targets}

Our focus is on research, international collaborations, clinical work, teaching and policy in health, disability and human development and to establish the NICHD as a permanent institute at one of the residential care centers for persons with intellectual disability in Israel in order to conduct model research and together with the four university schools of public health/medicine in Israel establish a national master and doctoral program in disability and human development at the institute to secure the next generation of professionals working in this often non-prestigious/low-status field of work.

\subsection{Contact}

Joav Merrick, MD, DMSc

Professor of Pediatrics, Child Health and Human Development

Medical Director, Health Services, Division for Intellectual and Developmental Disabilities, Ministry of Social Affairs and Social Services, POB 1260, IL-91012 Jerusalem, Israel

E-mail: jmerrick@zahav.net.il 
